\title{
Kinetics of Plasma Cytokines During and After Two Different Modalities of Extracorporeal Blood Purification in Critically III COVID-19 Patients
}

\section{Daniela Ponce ( $\nabla$ daniela.ponce@unesp.br)}

Universidade Estadual Paulista Júlio de Mesquita Filho https://orcid.org/0000-0002-6178-6938

\section{Welder Zamoner}

UNESP: Universidade Estadual Paulista Julio de Mesquita Filho

\section{Luis Eduardo Magalhães}

UNESP: Universidade Estadual Paulista Julio de Mesquita Filho

\section{Paula Gabriela Souza de Oliveira}

Universidade Estadual Paulista: Universidade Estadual Paulista Julio de Mesquita Filho

\section{Patricia Polla}

Clinical Hospital of Botucatu Medical School

\section{Alexandre Naime Barbosa}

UNESP: Universidade Estadual Paulista Julio de Mesquita Filho

\section{Marjorie de Assis Golim}

Universidade Estadual Paulista: Universidade Estadual Paulista Julio de Mesquita Filho

\section{Andre Luis Balbi}

UNESP: Universidade Estadual Paulista Julio de Mesquita Filho

\section{Research}

Keywords: COVID-19, cytokines, extracorporeal blood treatment

Posted Date: December 30th, 2020

DOI: https://doi.org/10.21203/rs.3.rs-136018/v1

License: (1) (1) This work is licensed under a Creative Commons Attribution 4.0 International License. Read Full License 


\section{Abstract}

Cytokine storm syndrome (CSS) has been documented in coronavirus disease 2019 (COVID-19) since the first reports of this disease. In the absence of vaccines or direct therapy for COVID-19, extracorporeal blood treatment (EBT) could represent an option for the removal of cytokines and may be beneficial to improve the clinical outcome of critically ill patients. Intermittent haemodialysis (IHD), using high flux (HF) or high cut-off membranes, and continuous renal replacement therapy (CRRT) could be used for blood purification in COVID-19 patients with CSS. To the best of our knowledge, cytokine kinetics during and after different types of EBT on COVID-19 patients have never been studied. In this study, we describe cytokine variation and removal during and after IHD and CRRT in COVID-19 patients with acute kidney injury (AKI).

Methods: Patients with COVID-19-related AKI according to Kidney Disease Improving Global Outcomes (KDIGO) criteria and admitted at Intensive Care Unit (ICU) were studied. Blood samples were collected at the start and end of both IHD using HF membranes (10 patients) and continuous venovenous haemodiafiltration (CVVHDF: 10 patients) in two sessions for measuring 13 different plasma interleukins and calculating the cytokine removal rate.

Results: We evaluated cytokine removal in patients with COVID-19-related AKI undergoing either prolonged IHD (10 patients) or CRRT (CVVHDF: 10 patients). There was no difference between the IHD and CVVHDF groups regarding mechanical ventilation, vasoactive drug use, age or prognostic scores. Patients treated by CRRT presented higher levels of IL-2 and IL-8 than patients treated by prolonged IHD at the start of dialysis. Cytokine removal ranged from $9-78 \%$. Patients treated by CRRT presented higher cytokine removal rates than those treated by prolonged IHD for IL-2, IL-6 IL-8, IP-10 and TNF. The removal rates of IL-4, IL-10, IL-1 $\beta$, IL-17A, IFN, MCP-1 and free active TGF-B1 were similar in the two groups. After one session of CVVHDF (24 h) the IL-2 and IL-1 $\beta$ levels did not vary significantly, whereas IL-4, IL-6, IL-8, IL-10, IL-17A, TNF, IFN, IP-10, MCP-1, IL-12p70 and free active TGF-B1 decreased by $33.8-76 \%$, and this decrease was maintained over the next $24 \mathrm{~h}$. In the prolonged IHD groups, IL-2, IL-6, TNF, IP-10 and IL-1 $\beta$ levels did not decrease significantly whereas IL-4, IL-8, IL-10, IL-17A, IFN, MCP-1, IL-12p70 and free active TGF-B1 decreased by $21.8-72 \%$. However, all cytokine levels returned to their initial values after $24 \mathrm{~h}$, despite their removal.

Conclusions: Cytokine removal is lower using prolonged IHD with HF membranes than by using CVVHDF, and IHD allows a transient and selective decrease in cytokines that can be correlated with mortality during CSS-related COVID-19.

\section{Introduction}

The World Health Organization declared coronavirus disease 2019 (COVID-19) a pandemic. Although the vast majority of COVID-19 patients suffer from mild symptoms, around $15 \%$ of individuals hospitalized for symptomatic COVID-19 infection require admission to intensive care units (ICUs) and, among them, 
$37 \%$ develop acute kidney injury (AKI) [1-3]. Of those with AKI, 14\% required renal replacement therapy (RRT), meaning that $5 \%$ of all patients hospitalized with COVID-19 required some form of dialysis support [4].

The aim of acute RRT is to support native kidney function in controlling acid-base and electrolyte derangements, as well as fluid overload, and to reduce the effects of AKI on non-renal organs, with the long-term goals of patient survival and renal recovery. Choice of the initial RRT modality is based on local availability and experience with a specific treatment, the patient's clinical status (haemodynamic stability, catabolic state, need for removal of large amounts of fluid, presence of life-threatening complications or acute brain injury) and the financial cost of therapy.

Based on these data, the Kidney Disease Improving Global Outcomes (KDIGO) Clinical Practice Guidelines for AKI recommend considering continuous and intermittent RRT modalities as complementary techniques [5]. Hybrid treatments such as prolonged intermittent haemodialysis (IHD) incorporate the advantages of both continuous RRT (CRRT) and IHD and are used worldwide in many ICUs [6-8]. They may be considered for haemodynamically unstable patients in situations where other forms of CRRT are not available, but data on comparative efficacy and harm are limited [8-12].

Extracorporeal blood treatment (EBT) has also been proposed as an approach to remove cytokines in patients with sepsis [13] and potentially could be beneficial in critically ill patients with COVID-19 [14]. The rationale for the use of EBT is that cytokine removal could prevent organ damage due to cytokine release syndrome. Among the EBT therapies both IHD, using high flux (HF) or high cut-off membranes (characterized by larger pore size and more effective clearance for medium-molecular-weight molecules such as cytokines), and CRRT can be considered.

In this paper, we performed a prospective study that aimed to describe and compare cytokine variations and removal during and after using IHD with HF membranes and CRRT in COVID-19 patients with AKI.

\section{Methodology}

\subsection{Patients}

A prospective cohort study of 20 hospitalized patients diagnosed with AKI related to COVID-19 undergoing RRT (IHD or HDF) was realized in the ICUs of a public and a tertiary university hospital in São Paulo, Brazil, from June to August 2020. Diagnosis of severe acute respiratory syndrome coronavirus 2 (SARS-CoV-2) was confirmed using reverse transcription polymerase chain reaction and the AKI diagnosis and classification were performed according to KDIGO criteria [6]. The need for dialysis was indicated by the gap between demand and capacity and also the presence of cytokine storm syndrome (CSS: continuous fever $>39^{\circ} \mathrm{C}$ ). Patients were treated with either IHD or CRRT according to local availability and the patient's clinical status. Patients with chronic kidney disease (stages IV and V), those needing kidney transplants and individuals under 18 years old were excluded. 
This study was registered in the Brazilian Registry of Clinical Trials (ReBEC: number RBR-62y3h7) and approved by the Research Ethics Committee of Botucatu School of Medicine (CAAE:

30451520.6.0000.5411). All research was performed following current regulations and written informed consent was obtained from all participants or their legal guardians.

\subsection{Ebt Procedures}

Vascular access was obtained using 12-Fr dual-lumen catheters in an internal jugular vein.

\subsubsection{Prolonged Ind}

Sessions lasting $6 \mathrm{~h}$ were performed with blood flows of $200 \mathrm{ml} / \mathrm{min}$ and dialysate flows of $300 \mathrm{ml} / \mathrm{min}$. We used a Fresenius 4008S ARrT Plus dialysis machine (Fresenius Medical Care AG, Bad Homburg, Germany) and HF membranes (polyethersulfone filters, surface area $1.7 \mathrm{~m}^{2}$; Nipro, Germany). The HF membranes were defined according to an estimated pore size of $5 \mathrm{~nm}$, resulting in an in vitro cut-off point of at least $40 \mathrm{kDa}$ (at least $30 \mathrm{kDa}$ for in vivo) and an ultrafiltration coefficient of $>20 \mathrm{mmHg}$.

During the sessions, patients were anticoagulated with an initial 50-100 IU/kg bolus dose of heparin and then at 500-1000 IU/h over the following hours. In cases of contraindication to anticoagulation, the system was washed with $50 \mathrm{ml}$ of $0.9 \%$ sodium chloride every 30 min throughout the entire procedure. The concentrations of bicarbonate (26-36 mEq/l), potassium (1-3 mEq/l), sodium (140-145 mEq/l) and calcium (2.5-3.5 mEq/l) in the dialysis bath were adjusted according to examination and the individual needs of the patients. The ultrafiltration rate did not exceed $500 \mathrm{ml} / \mathrm{h}$ and the bath temperature was $35-35.5^{\circ} \mathrm{C}$.

\subsubsection{CRRT}

CRRT was operated as continuous venovenous haemodiafiltration (CVVHDF) using an AN69 membrane (ST 100, Baxter) through a Prismaflex CRRT system (Baxter). Due to the clinical conditions, blood flow rates were kept in the range 140-180 ml/min and dialysis doses were $30 \mathrm{ml} / \mathrm{kg} / \mathrm{h}$. Patient fluid removal is tailored to the individual's volume status $(100-250 \mathrm{ml} / \mathrm{h})$ and the filter was changed every $48 \mathrm{~h}$.

A regional citrate anticoagulation regimen was adopted, with anticoagulant doses adjusted individually according to the patients' coagulation state, and a sterile citrate-containing solution without calcium was infused in predilution mode. In postdilution, a sterile saline solution containing calcium chloride was infused to maintain the postfilter $\left(\mathrm{Ca}^{2+}=0.25-0.35 \mathrm{mmol} / \mathrm{l}\right)$ and arterial line $\left(\mathrm{Ca}^{2+}=1-1.2 \mathrm{mEq} / \mathrm{l}\right)$.

\subsubsection{Cytokine removal during dialysis}

We measured plasma concentrations of cytokines (IL-2, IL-4, IL-6, IL-8, IL-10, IL-17A, TNF, IFN, IP-10, IL12p70, MCP and free active TGF-B1) at the initial $\left(T_{0}\right)$ and final $\left(T_{f}\right)$ dialysis session ( $6 \mathrm{~h}$ for prolonged 
IHD and $24 \mathrm{~h}$ for CRRT) over 2 days. Blood samples and dialysate were collected in non-heparinized tubes, immediately centrifuged at $4000 \mathrm{rpm}$ for $10 \mathrm{~min}\left(4^{\circ} \mathrm{C}\right)$ and then subsequently stored at $-70^{\circ} \mathrm{C}$ until assayed. Quantification of cytokines was determined by enzyme-linked immunosorbent assay

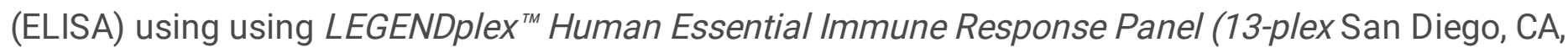
USA) according to the manufacturer's instructions. Assay sensitivity limits were $0.22 \mathrm{pg} / \mathrm{mL}$ for IL-2, $2.84 \mathrm{pg} / \mathrm{mL}$ for IL-4, $2.0 \mathrm{pg} / \mathrm{mL}$ for IL-6, $2.50 \mathrm{pg} / \mathrm{mL}$ for IL-8, 3.14 pg/mL for TNF-a, $1.25 \mathrm{pg} / \mathrm{mL}$ for IL-10, $6.32 \mathrm{pg} / \mathrm{mL}$ for IP-10, $2.27 \mathrm{pg} / \mathrm{mL}$ for IL-1b, $1.8 \mathrm{pg} / \mathrm{mL}$ for MCP-1, $1.36 \mathrm{pg} / \mathrm{mL}$ for IL-17A, $3.0 \mathrm{pg} / \mathrm{mL}$ for INF, and $1.89 \mathrm{pg} / \mathrm{mL}$ for IL-12p70. All measured cytokines had molecular weight between 8 and $35 \mathrm{kDa}$ (IL-2: 15 kDa, IL4: 18 kDa, IL-6: 28 kDa, IL-8: 12 kDa, IL-10:19 kDa, IL -8: 8 kDa, TNF 17 kDa, MCP-1: $10 \mathrm{kDa}$, IFN 18 kDa, IL 17A: 35 kDa, IL12p70: 35 kDa).

We calculated cytokine removal according to the formula $C_{\mathrm{f}}-C_{0} / C_{\mathrm{f}} \times 100$, where $C_{0}$ is the cytokine concentration at the initial dialysis session and $C_{\mathrm{f}}$ is the cytokine concentration

\subsection{Statistical Analysis}

SPSS 19.0 software was used for statistical analysis. Frequency measures were calculated for categorical variables; measurement of continuous variables conforming to a normal distribution were expressed as mean \pm standard deviation and those not conforming to a normal distribution were expressed as median with interquartile range. Comparison of data before and after treatment was performed by paired $t$-test or non-parametric test for continuous variables and by chi-squared test for categorical variables.

\section{Results}

We evaluated cytokine removal in 20 patients with COVID-19-related AKI undergoing prolonged IHD (10 patients) or CRRT (CVVHDF). There was no difference between the IHD and CVVHDF groups regarding mechanical ventilation, vasoactive drug use, age or prognostic scores (APACHE II and SOFA). On dialysis, these patients presented elevated levels of cytokines measured at the start of the dialysis session, as shown in Table 1. Patients treated by CRRT presented higher levels of IL-2 and IL-8 than patients treated by prolonged IHD at $T_{0}$ (before the start of dialysis). 
Table 1

Clinical and laboratory characteristics in AKI-related to COVID patients admitted in ICU according to renal acute support modality

\begin{tabular}{|c|c|c|c|c|}
\hline VARIABLES & General $(n=20)$ & CRTT $(n=10)$ & $\begin{array}{l}\text { Prolonged iHD }(n= \\
\text { 10) }\end{array}$ & $\begin{array}{l}\text { p- } \\
\text { value }\end{array}$ \\
\hline Male sex (\%) & $12(60)$ & $6(60)$ & $6(60)$ & 1 \\
\hline Age (years) * & $59.2 \pm 13.8$ & $60.2 \pm 13.3$ & $57.8 \pm 13.9$ & 0.62 \\
\hline $\begin{array}{l}\text { Arterial hypertension } \\
(\%)\end{array}$ & $9(45)$ & $4(40)$ & $5(50)$ & 0.45 \\
\hline Diabetes mellitus (\%) & $10(50)$ & $6(60)$ & $4(40)$ & 0.36 \\
\hline Obesity (\%) & $11(55)$ & $6(60)$ & $5(50)$ & 0.81 \\
\hline ATN-ISS * & $0.65 \pm 0.13$ & $0.68 \pm 0.13$ & $0.61 \pm 0.14$ & 0.36 \\
\hline APACHE II * & $22.1 \pm 8.1$ & $23.5 \pm 8.2$ & $20.2 \pm 8.1$ & 0.19 \\
\hline SOFA & $10.1 \pm 1.1$ & $11.5 \pm 1.2$ & $9.9 \pm 1.1$ & 0.23 \\
\hline $\begin{array}{l}\text { Mechanical ventilation } \\
(\%)\end{array}$ & $20(100)$ & $10(100)$ & $100(100)$ & 1 \\
\hline Noradrenaline use (\%) & $13(65)$ & $6(60)$ & $7(70)$ & 0.43 \\
\hline Death (\%) & $15(75)$ & $7(60)$ & $8(80)$ & 0.21 \\
\hline \multicolumn{5}{|l|}{$\begin{array}{l}\text { Plasma IL at T0 } \\
(\mathrm{pg} / \mathrm{mL})\end{array}$} \\
\hline IL-4 & $33(15-84)$ & $35(15-84)$ & $20(15-54)$ & 0.21 \\
\hline IL-2 & $6.8(2.7-11)$ & $9.8(7.7-12)$ & $3.3(1.5-5.7)$ & 0.008 \\
\hline IL-6 & $\begin{array}{l}139.1(108,1- \\
269,0)\end{array}$ & $\begin{array}{l}129.1(101,1- \\
269,0)\end{array}$ & 147.4(112.1-269.8) & 0.9 \\
\hline IL-8 & $59.1(20,1-101,0)$ & $71.1(30-139,0)$ & $29.1(17-69,0)$ & 0.005 \\
\hline IL-10 & $35.1(21,1-69,0)$ & $41.1(31-108,0)$ & $29.1(14-49,0)$ & 0.07 \\
\hline IL-17A & $10.1(5,1-19,0)$ & $10.9(5,4-17,0)$ & $9.8(4,1-20,0)$ & 0.88 \\
\hline TNF & $14.1(10,1-69,0)$ & $16.1(11,1-64,0)$ & $13.1(9,1-63,0)$ & 0.72 \\
\hline IFN & $35.1(20,1-88,0)$ & $37.1(22,1-86,0)$ & $34.1(19,1-84,0)$ & 0.73 \\
\hline MCP-1 & $\begin{array}{l}408.9(240,1- \\
819,4)\end{array}$ & $\begin{array}{l}428.9(340,1- \\
649,4)\end{array}$ & $398.9(180,1-1049,4)$ & 0.91 \\
\hline
\end{tabular}

Abbreviations: AKI: acute kidney injury; ICU: intensive care unit; ATN-ISS: Acute Tubular Necrosis Individual Severity Score; APACHE II: Acute Physiology and Chronic Health disease Classification System II score; SOFA: Sequential Organ Failure Assessment score; T0 = at initial dialysis session; ILinterleucin 


\begin{tabular}{|c|c|c|c|c|}
\hline VARIABLES & General $(n=20)$ & CRTT $(n=10)$ & $\begin{array}{l}\text { Prolonged iHD }(n= \\
\text { 10) }\end{array}$ & $\begin{array}{l}\text { p- } \\
\text { value }\end{array}$ \\
\hline IP-10 & $\begin{array}{l}619.8(487.7- \\
1412)\end{array}$ & $\begin{array}{l}489.8(447.7- \\
1212)\end{array}$ & $689.3(529.5-155.7)$ & 0.82 \\
\hline IL-12p70 & $14.1(9,1-29,0)$ & $17.1(8,1-24,0)$ & $10.1(7,1-33,0)$ & 0.21 \\
\hline Free active TGF-B1 & $64.1(29,1-129,0)$ & $68.1(28,1-124,0)$ & $61.1(27,1-133,0)$ & 0.41 \\
\hline IL-1b & $13.1(9,1-43,0)$ & $12.1(9,9-39,0)$ & $13.4(8,9-40,0)$ & 0.73 \\
\hline \multicolumn{5}{|c|}{$\begin{array}{l}\text { Abbreviations: AKI: acute kidney injury; ICU: intensive care unit; ATN-ISS: Acute Tubular Necrosis - } \\
\text { Individual Severity Score; APACHE II: Acute Physiology and Chronic Health disease Classification } \\
\text { System II score; SOFA: Sequential Organ Failure Assessment score; TO = at initial dialysis session; IL- } \\
\text { interleucin }\end{array}$} \\
\hline
\end{tabular}

Table 2 provides details of cytokine removal during the dialysis session. Cytokine removal ranged from 9-78\%. Patients treated by CRRT presented higher cytokine removal rates than those treated by prolonged IHD for IL-2, IL-6, IL-8, IP-10 and TN. The removal rates of IL-4, IL-10, IL-1 $\beta$, IL-17A, IFN, MCP-1 and free active TGF-B1 were similar in the two groups. 
Table 2

Cytokines removal during prolonged $\mathrm{iHD}$ and CVVHDF

\begin{tabular}{|lllll|}
\hline $\begin{array}{l}\text { Cytokines } \\
\text { removal (\%) }\end{array}$ & $\begin{array}{l}\text { General }(n=40 \\
\text { sessions) }\end{array}$ & $\begin{array}{l}\text { CRTT }(\mathbf{n}=20 \\
\text { sessions) }\end{array}$ & $\begin{array}{l}\text { Prolonged iHD }(\mathbf{n}=20 \\
\text { sessions })\end{array}$ & $\begin{array}{l}\text { p- } \\
\text { value }\end{array}$ \\
\hline IL-4 & $43(11-74)$ & $47(19.5-81)$ & $40(2.5-62)$ & 0.41 \\
\hline IL-2 & $6.1(2.1-9.4)$ & $7(3.3 .-9)$ & $2.8(1.5-6.7)$ & 0.008 \\
\hline IL-6 & $23(11-50.2)$ & $32(19.5-44)$ & $14(2.1-51)$ & 0.04 \\
\hline IL-8 & $63(31-76.1)$ & $76(59.5-91)$ & $44(12.5-62)$ & 0.018 \\
\hline IL-10 & $43(11-74.4)$ & $47(19.5-81)$ & $40(2.5-62)$ & 0.07 \\
\hline IL-17A & $73(37.2-84.9)$ & $75(41.5-88)$ & $72(32.5-92)$ & 0.87 \\
\hline TNF & $23(11-5.44)$ & $33(19.5-61)$ & $9(5.5-32)$ & 0.04 \\
\hline IFN & $49(11-74.1)$ & $48(9.5-81)$ & $54(21-72)$ & 0.53 \\
\hline MCP-1 & $28(11-54.6)$ & $33(19.5-61)$ & $21(2.5-32)$ & 0.63 \\
\hline IP-10 & $31(21-44.1)$ & $48(51.5-66.3)$ & $12.5(3.5-31.2)$ & 0.98 \\
\hline IL-12p70 & $70.5(31-84.2)$ & $71(29.5-88.1)$ & $69(32.5-82.9)$ & 0.41 \\
\hline Free active TGF- & $43(1.11-74.7)$ & $47(19.5-81)$ & $40(2.5-62)$ & 0.89 \\
\hline B1 & $13(8.5-19.2)$ & $15(9.2-2.61)$ & $12(8.5-16.2)$ & \\
\hline IL-1b & & & & \\
\hline iHD: intermittent hemodilaysis; CVVHDF: continuous venovenous hemodifiltration & \\
\hline
\end{tabular}

After one session of CVVHDF ( $24 \mathrm{~h}$ ) the IL-2 and IL-1 $\beta$ levels did not vary significantly whereas IL-4, IL-6, IL-8, IL-10, IL-17A, TNF, IFN, IP-10, MCP-1, IL-12p70 and free active TGF-B1 decreased by 33.8-76\%, and this decrease was maintained over the next $24 \mathrm{~h}$, as shown in Fig. 1. In the prolonged IHD groups, IL-2, IL6, TNF, IP-10 and IL-1 $\beta$ did not decrease significantly but IL-4, IL-8, IL-10, IL-17A, IFN, MCP-1, IL-12p70 and free active TGF-B1 decreased by $21.8-72 \%$. However, all cytokine levels returned to their initial values, despite their removal by prolonged IHD (Fig. 2).

\section{Discussion}

COVID-19 is an epidemic of global concern and previous studies have pointed out CSS as a possible cause of aggravation [16]. CSS is a systemic inflammatory reaction that releases a series of cytokines, including TNF- $\alpha$, IL-1 $\beta$, IL-2, IL-6, IFN- $\alpha$ and MCP-1. These cytokines induce immune cells to release large amounts of free radicals, which are the leading cause of multiple organ failure, including AKI [17].

EBT is considered an important means for removing cytokines from patients with sepsis and also the main advocated technology of organ support therapy for patients with severe COVID-19. Prolonged IHD 
(using HF or high cut-off membranes) and CVVHDF are two different modalities of EBT that have the functions of supporting renal function, adsorbing endotoxins and removing inflammatory mediators [18].

Prolonged IHD is a hybrid treatment that incorporates the advantages of both CRRT and IHD and is used worldwide in many ICUs but mainly in developing countries [6-8] where other forms of CRRT are not available due to the high costs. A systematic review and meta-analysis including 17 studies during 2000-2014 ( 7 randomized controlled trials and 10 observational studies involving 533 and 675 patients, respectively) focused on the impact of prolonged intermittent RRT and CRRT on mortality and renal recovery [12] and showed no difference in mortality between the two modalities.

We evaluated cytokine removal in patients with COVID-19-related AKI undergoing prolonged IHD using HF membranes or CVVHDF. Our study showed that cytokine removal ranged from 9-78\%. Patients treated by CRRT presented higher cytokine removal rates for IL-2, IL-6, IL-8, IP-10 and TNF than patients treated by prolonged IHD. The removal rates of IL-4, IL-10, IL-13, IL-17A, IFN, MCP-1 and free active TGF-B1 were similar in the two groups.

After one session of CVVHDF ( $24 \mathrm{~h}$ ) the IL-2 and IL-1 $\beta$ levels did not vary significantly whereas IL-4, IL-6, IL-8, IL-10, IL-17A, TNF, IFN, IP-10, MCP-1, IL-12p70 and free active TGF-B1 decreased by $33.8-76 \%$, and this decrease was maintained over the next $24 \mathrm{~h}$. These findings are in accordance with previous studies $[10,19]$. The application of EBT is helpful for the removal of cytokines and may be beneficial for improving the clinical outcome of critically ill patients. Commonly used EBT therapies are plasma exchange and high-dose CRRT. Previous studies have suggested that therapeutic plasma exchange and CRRT play an important role in the treatment of severe haemophagocytic syndrome and sepsis in critically ill children and adult patients with AKI by reducing the levels of cytokines (such as TNF- $a$ and IL6) and improving the SOFA (sequential organ failure assessment) score after the application of CRRT [19-22].

CRRT with the recently developed CytoSorb and oXiris (commercially available haemoadsorption and haemodiafilters that utilize EBT) has been designed to reduce systemic cytokine burden. Numerous case reports and case series have suggested improved clinical outcomes with CytoSorb in patients with septic shock [23].

Recently, Ronco et al. [23] showed that EBT with oXiris decreased the serum IL-6 level, attenuated systemic inflammation, improved multi-organ dysfunction and reduced the expected ICU mortality rate in 37 patients with COVID-19. This shows that CRRT has become a multi-organ support rather than pure renal replacement among these patients, due to the development of new medical and membrane technology, and provides opportunity and conditions for further treatment that may improve patient outcome.

In our study, we observed that prolonged IHD using HF membranes only partially and transiently removed plasma IL-4, IL-8, IL-10, IL-17A, IFN, MCP-1, IL-12p10 and free active TGF-B1, and did not remove IL-2, IL-6, TNF, IP-10 or IL-1 $\beta$. The kinetics of plasma cytokine levels after IHD in patients with COVID-19-related AKI 
have not been reported previously and studies on sepsis-related AKI are scarce. Mayeur et al. [24] evaluated cytokine removal in 10 patients with sepsis-related AKI treated with IHD using HF membranes (polymethymethacrylate haemodialyser). During IHD, the IL-6 level did not vary significantly whereas IL-8 and IL-10 were reduced by $31.8 \pm 21.2 \%$ and $36.3 \pm 26 \%$, respectively. After 3 h, both IL-8 and IL-10 returned to their initial values.

The rebound phenomenon, which can be applied to the shift of soluble molecules from tissues to the intravascular compartment through a concentration gradient until a new equilibrium is reached, can explain the transient cytokine reduction. Cytokines are heavier and less diffusive molecules than urea or potassium, therefore this rebound could reflect a cytokine concentration gradient between tissue and vascular compartments that appeared during IHD. After IHD, a progressive release of cytokines from dialysis-induced hypoperfused tissue to the intravascular compartment may occur until a new equilibrium is reached.

There were several limitations to this study: it was a descriptive research study without a control group due to the specificity of the disease; the small sample size may have led to deviation of the results; we did not analyse the cytokine levels in dialysate and thus did not calculate their clearance; and we did not evaluate the association between cytokine removal and stabilization of haemodynamic status and improvement of organ function.

\section{Conclusion}

Despite these limitations, our results show that cytokine removal is lower by prolonged IHD using HF membranes than by CVVHDF. Furthermore, prolonged IHD allows a transient and selective decrease in cytokines that can be correlated with mortality during septic shock or CSS-related COVID-19.

The hypothesis that reduction of overexpressed cytokines through EBT can induce a significant decrease in leukocyte adhesion and plasma extravasation, which leads to improvement of the microcirculation disorder [19] and contributes to improve the haemodynamic status, needs to be explored further in larger studies.

\section{Declarations}

\section{Ethics approval and consent to participate}

This study was registered in the Brazilian Registry of clinical trials (ReBEC) under number RBR-62y3h7 and was approved by the Research Ethics Committee of Botucatu School of Medicine (CAAE 30451520.6.0000.5411).

\section{Consent for publication}


Not applicable

\section{Availability of data and materials}

All data generated or analysed during this study can be included in this published article as supplementary information files.

\section{Competing interests}

The authors declare that they have no competing interests

\section{Funding}

The study has no funding

\section{Authors' contributions}

LEM, PGS and WZ collected the data. DP and WZ DP analyzed and interpreted the patient data regarding the acute kidney injury disease and dialysis. MAG performed cytokines analysis. DP and AB had the a major contributor in writing the manuscript. DP and AB performed the statistical analysis All authors read and approved the final manuscript.

\section{References}

1. Huang C, Wang Y, Li X, Ren L, Zhao J, Hu Y. Clinical features of patients infected with 2019 novel coronavirus in Wuhan, China. Lancet. 2020;395: 497-506 https://doi.org/10.1016/S01406736(20)30183-5.

2. Richardson S, Hirsch JS, Narasimhan M, Crawford JM, McGinn T, Davidson KW, et al. Presenting characteristics, comorbidities, and outcomes among 5700 patients hospitalized with COVID-19 in the New York City area. JAMA.2020. https://doi.org/10.1001/jama.2020.6775.

3. Channappanavar R, Perlman S. Pathogenic human coronavirus infections: causes and consequences of cytokine storm and immunopathology. Semin Immunopathol. 2017;39:529-39.

4. Hirsch J, Ng J, Ross D, Sharma P, Shah H, Barnett R, et al. Acute kidney injury in patients hospitalized with COVID-19. Kidney Int. 2020; https://doi.org/10.

5. Monard C, Rimmelé T, Ronco C. Extracorporeal blood purification therapies for sepsis. Blood Purif. 2019;47(suppl 3):2-15.

6. Ponce $\mathrm{D}$, Abrão JM, Albino BB, et al. Extended daily dialysis in acute kidney injury patients: metabolic and fluid control and risk factors for death. PLoS One. 2013;8:e81697.

7. Kumar VA, Craig M, Depner TA, et al. Extended daily dialysis: a new approach to renal replacement for acute renal failure in the intensive care unit. Am J Kidney Dis. 2000;36: 294-300. 
8. Albino BB, Balbi AL, Abrao JM, et al. Dialysis complications in acute kidney injury patients treated with prolonged intermittent renal replacement therapy sessions lasting 10 versus 6 hours: results of a randomized clinical trial. Artif Organs. 2015;39:423-31.

9. Fieghen HE, Friedrich JO, Burns KE, et al. The hemodynamic tolerability and feasibility of sustained low efficiency dialysis in the management of critically ill patients with acute kidney injury. BMC Nephrol. 2010;11:32.

10. Marshall MR, Ma T, Galler D, et al. Sustained low-efficiency daily diafiltration (SLEDD-f) for critically ill patients requiring renal replacement therapy: towards an adequate therapy. Nephrol Dial Transplant. 2004;19:877-84.

11. Holt BG, White JJ, Kuthiala A, et al. Sustained low-efficiency daily dialysis with hemofiltration for acute kidney injury in the presence of sepsis. Clin Nephrol. 2008;69:40-6.

12. Kumar VA, Yeun JY, Depner TA, et al. Extended daily dialysis vs. continuous hemodialysis for ICU patients with acute renal failure: a two-year single center report. Int J Artif Organs. 2004;27:371-9.

13. Ronco C, Reis T, Husain-Syed F. Management of acute kidney injury in patients with COVID-19. Lancet. 2020; https://doi.org/10.1016/S2213-2600(20)30229-0.

14. Ronco C, Reis T. Kidney involvement in COVID-19 and rationale for extracorporeal therapies. Nature Reviews Nephr. 2020; https://doi.org/10. 1038/s41581-020-0284-7.

15. Kidney Disease: Improving Global Outcomes (KDIGO) Acute Kidney Injury Work Group. KDIGO clinical practice guideline for acute kidney injury.Kidney Int Suppl 2012; 2:1-138.

16. Ronco, C, Reis T, De Rosa S. Coronavirus epidemic and extracorporeal therapies in intensive care: si vis pacem para bellum. Blood Purif 2020; https://doi.org/10.1159/000507039 (2020).

17. Moore JB, June CH. Cytokine release syndrome in severe COVID-19. Science. 2020 May; 368(6490): 473-4.

18. Villa G, Zaragoza JJ, Sharma A, Neri M, Gaudio R, Ronco C. Cytokine Removal with High Cut-Off Membrane: Review of Literature. aBlood Purif 2014;38:167-73.

19. Madelaine T, Page M, Prothet J, Ber CE, Crozon J, Allaouchiche B, et al: Super high-flux continuous hemodialysis in septic shock: a case report. Nephrol Ther 2013; 9: 497-500.

20. Kade G, Wiśniewska M, Lubas A, Rzeszotarska A, Korsak J: The treatment of septic shock with continuous venovenous hemodialysis using high cut-off dialyzer in patient after immediate circulatory arrest. Przegl Lek 2013;70: 698-700.

21. Chelazzi C, Giugni D, Giannoni C, Villa G, De Gaudio AR: Use of continuous venovenous hemodiafiltration with a high cutoff membrane in a patient with severe acute pancreatitis. $J$ Nephrol 2012; 2: 78-81.

22. Ronco C, Bonello M, Bordoni V, Ricci Z, D'Intini V, Bellomo R, et al: Extracorporeal therapies in nonrenal disease: treatment of sepsis and the peak concentration hypothesis. Blood Purif 2004; 22 : 164-174. 
23. Villa G, Romagnoli S, De Rosa S, Greco M, Resta M, Montin DP et al. Blood purification therapy with a hemodiafilter featuring enhanced adsorptive properties for cytokine removal in patients presenting COVID-19: a pilot study. Critical Care (2020) 24:605

24. Mayeur N, Rostaing L, Nogier MB, Jaafar A, Cointault, Kamar N et al. Kinetics of plasmatic cytokines and cystatin $\mathrm{C}$ during and after hemodialysis in septic shock-related acute renal failure. Critical Care 2010, 14:R115

\section{Figures}

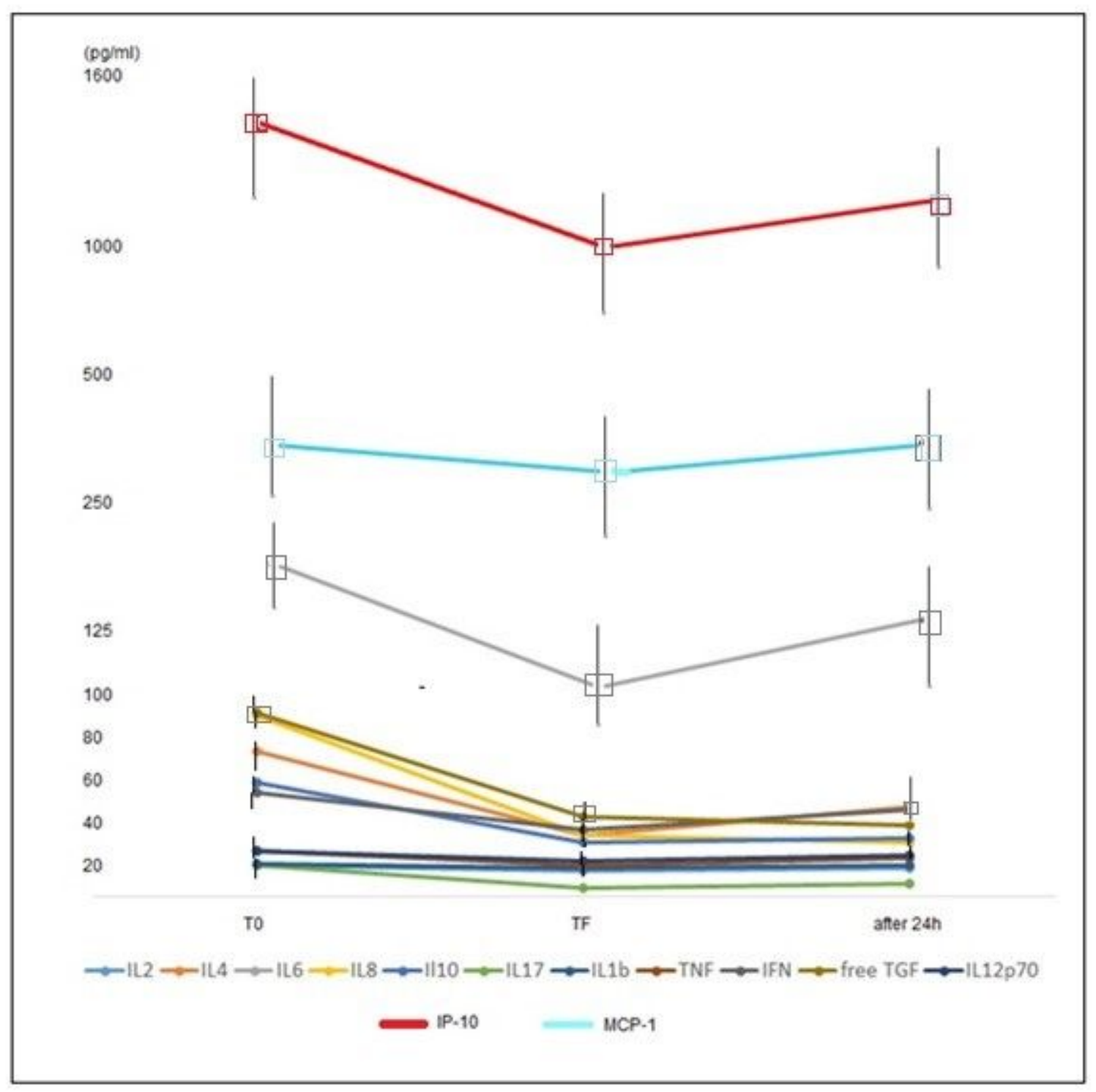


Figure 1

Variations of cytokine levels during and 24h after end of CRRT T0: start of dialysis; TF: end of dialysis

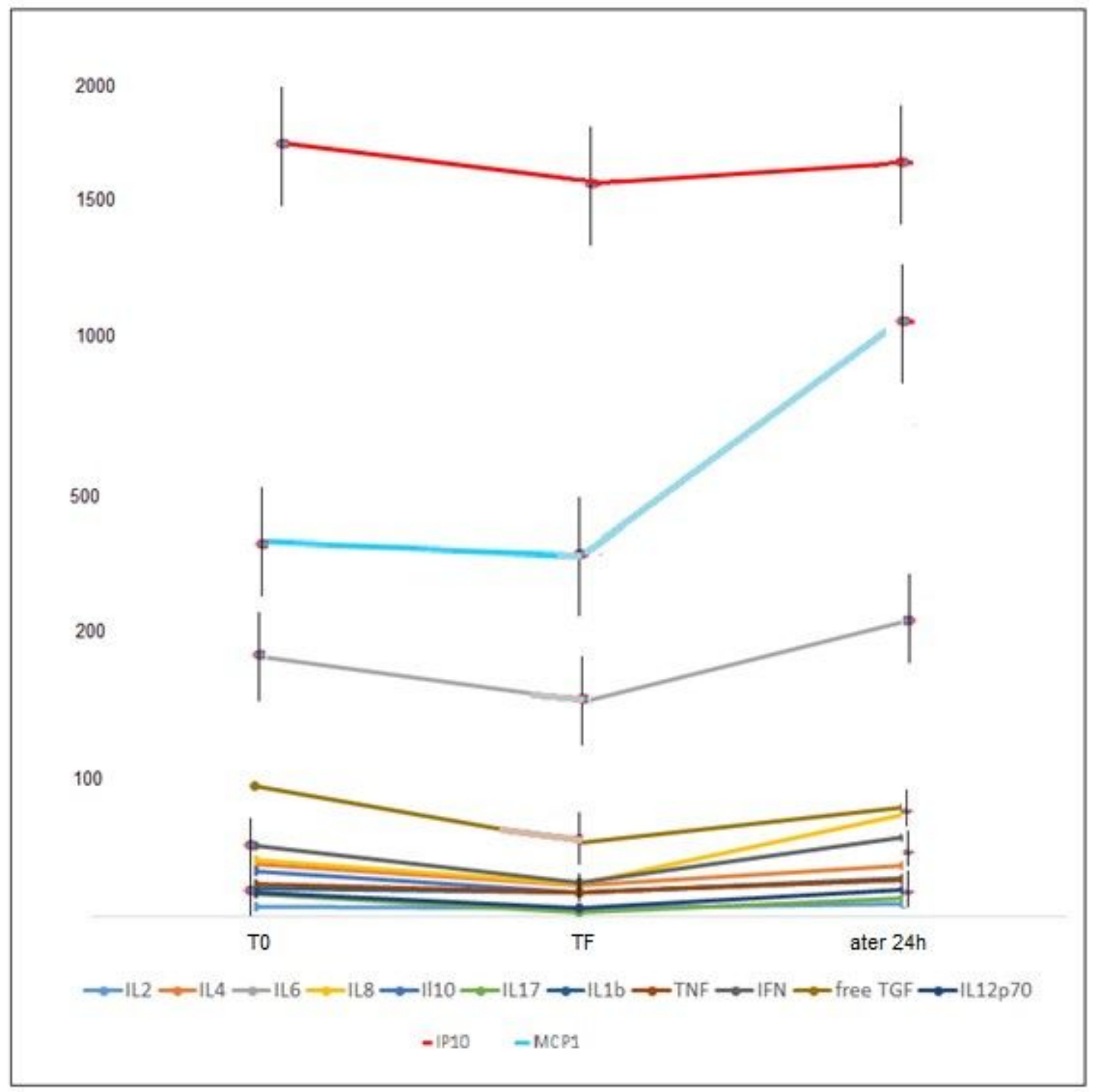

Figure 2

Variations of cytokine levels during and $24 \mathrm{~h}$ after end of prolonged iHD T0: start of dialysis; TF: end of dialysis 